Furthermore, as venous blood that returned from the lower half of the body via the femoral artery retrogradely perfuses the brain, it remains unclear whether the oxygen level in the venous blood, which may depend on the metabolic state of the visceral organs, can adequately meet the demands of the brain tissue.

In the surgical treatment of complex aortic disease, it is important to avoid complications related to the diseased aorta and to reduce the potential for neurologic injury. We have devised the technique of total body retrograde perfusion using axillary artery cannulation, which does not require occlusion of the distal descending aorta for the purpose of perfusing the brain and precluding the suction of air. When the long multipored cannula is positioned near the diaphragm, the continuous retrograde perfusion through the multipored cannula at this site can perfuse the brain and the visceral organs simply by adjusting the operating table and precludes air suction in the lower half of the body. As the vena caval system is located lower than the right ventricle, main pulmonary artery, and aortic arch, the retrograde flow can be determined and adjusted by monitoring both the pulmonary artery pressure and the pressure in the superior vena cava (Fig 3).
In contrast to the technique proposed by Takamoto and associates, ${ }^{2}$ our method can achieve retrograde perfusion of the brain with adequately oxygenated blood, in addition to minimizing the risk of debris emboli to the brain and other important visceral organs. This modified technique is a safer alternative for operations on the descending thoracic aorta.

\section{REFERENCES}

1. Spentpetery S, Crisler C, Grinnan GLB. Deep hypothermic arrest and left thoracotomy for repair of difficult thoracic aneurysms. Ann Thorac Surg 1993;55:830-3.

2. Takamoto S, Okita Y, Ando M, Morota T, Handa N, Kawashima Y. Retrograde cerebral circulation for distal aortic arch surgery through a left thoracotomy. J Card Surg 1994;9: 576-83.

3. Westaby S, Katsumata T. Proximal aortic perfusion for complex arch and descending aortic disease. J Thorac Cardiovasc Surg 1998;115:162-7.

4. Sabik JF, Lytle BW, McCarthy PM, Cosgrove DM. Axillary artery: an alternative site of arterial cannulation for patients with extensive aortic and peripheral vascular disease. J Thorac Cardiovasc Surg 1995;109:885-91.

\title{
THYMOMA ENCASING LAST PATENT VEN GRAFT TO THE HEART
}

\author{
Michael T. Jaklitsch, MD, John G. Byrne, MD, and Carlos Mery, Boston, Mass, and Monterrey, Mexico
}

A 64-year-old man had progressive weakness 11 years after coronary artery bypass surgery. In 1987, he received 4 vein grafts to the left anterior descending (LAD), the first obtuse marginal, the ramus, and the posterior descending arteries after a myocardial infarction. During the summer of 1998, he began having progressive ptosis, slurred speech, fatigue, and myalgias. Serum anti-acetylcholine-receptor antibodies and an edrophonium test confirmed the clinical diagnosis of myasthenia gravis. Pyridostigmine, $60 \mathrm{mg} 3$ times a day, produced symptomatic improvement.

A chest computed tomographic scan identified a $3.5-\mathrm{cm}$ homogeneous anterior mediastinal mass anterior to the pul-

From the Divisions of Thoracic Surgery and Cardiac Surgery, Brigham and Women's Hospital, Harvard Medical School, Boston, Mass, and ITESM Medical School, Monterrey, Mexico.

Received for publication May 3, 1999; accepted for publication May 7, 1999.

Address for reprints: Michael T. Jaklitsch, MD, Division of Thoracic Surgery, Brigham and Women's Hospital, 75 Francis St, Boston, MA 02115 .

J Thorac Cardiovasc Surg 1999;118:561-3

Copyright (C) 1999 by Mosby, Inc.

$0022-5223 / 99 \$ 8.00+0 \quad \mathbf{1 2 / 5 4 / 9 9 9 3 1}$ monary artery consistent with a thymoma (Fig 1). A partially calcified vein graft was contiguous with the tumor.

Coronary angiography revealed severe native vessel disease (90\% left main, $100 \%$ proximal LAD, $100 \%$ first obtuse marginal, and $100 \%$ proximal right coronary artery) with complete occlusion of 3 of the 4 grafts (first obtuse marginal, ramus, and posterior descending artery). The LAD graft, which appeared to pass through the tumor, was the only patent vessel to the coronary circulation. Left ventriculography showed no wall motion abnormalities and an ejection fraction of 0.67 .

We prepared to remove the only patent vessel providing coronary circulation along with the tumor. The left saphenous vein was harvested. The patient was heparinized and cardiopulmonary bypass (CPB) was established via the left femoral artery and vein before the chest incision. A redo sternotomy was performed without complications and a $4.2-\mathrm{cm}$ upper anterior mediastinal mass was exposed. Manipulation of the sternum was minimized until both pleura were opened wide. The thymoma was attached to the pericardium and the pulmonary artery conus where the pericardium had been opened in 1987. We observed $1-\mathrm{cm}$ erosion into the left pleural space anterior to the hilum without evidence of drop metastases. 

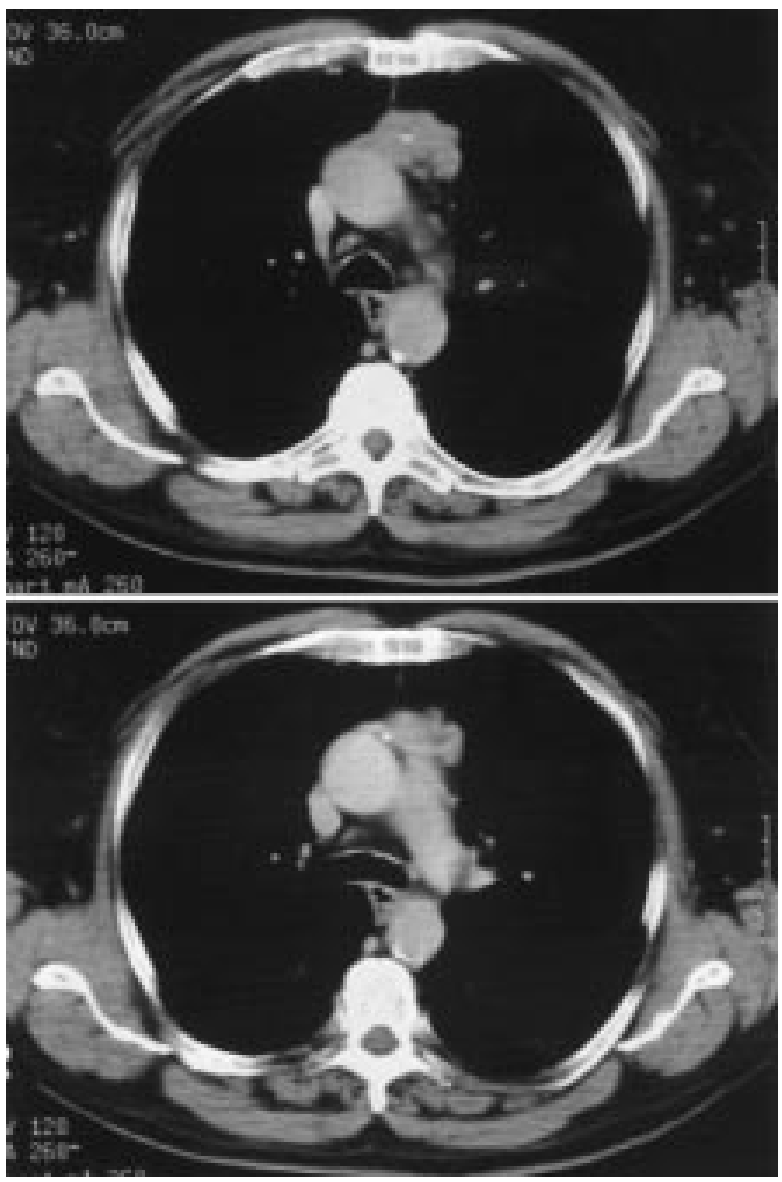

Fig 1. Computed tomography of the chest shows a calcified vein graft in the middle of an anterior mediastinal mass (top). A more caudal cut shows a patent vein graft passing between the aorta and the thymic tumor (bottom).

The patient was weaned from CPB but the heparin was not reversed. The left internal thoracic artery was prepared for in situ grafting. Initial dissection of the tumor off CPB included the cervical horns of the thymus, division of the thymic veins draining into the innominate vein, and establishment of the lateral margin of resection just anterior to the phrenic nerves. This provided a $1-\mathrm{cm}$ margin from the area of pleural erosion. This dissection was performed without manipulation of the LAD vein graft, which appeared to pass directly through the tumor.

$\mathrm{CPB}$ was reestablished and the patient cooled to $25^{\circ} \mathrm{C}$. The aorta was crossclamped and the heart protected with antegrade and retrograde boluses of cold blood cardioplegic solution. The thymoma was removed en bloc with the patent saphenous vein graft to the LAD and the occluded vein graft to the ramus (Fig 2).

The left saphenous vein was fashioned as a sequential graft to the first and second obtuse marginal arteries. The left internal thoracic artery was grafted to the LAD distal to the previous vein graft insertion. The patient was rewarmed and

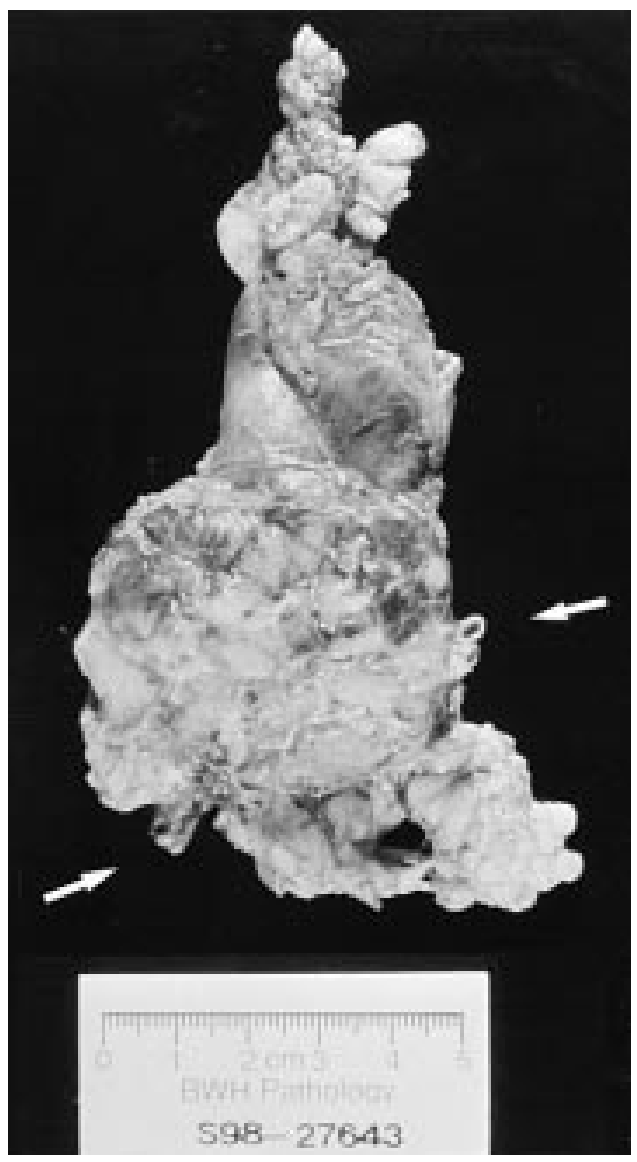

Fig 2. Gross pathologic specimen viewed from the deep margin shows 2 vein grafts encased by thymoma (arrows). The graft to the ramus branch was occluded. Nearly the entire cardiac blood supply flowed through the patent LAD graft.

weaned from CPB without difficultly. He was extubated on postoperative day 1 and discharged on day 6 receiving $30 \mathrm{mg}$ pyridostigmine 3 times a day.

Pathologic analysis revealed an epithelial-predominant thymoma with invasion of the surrounding fat. The tumor wrapped around, but did not invade, the walls of the saphenous vein grafts. The deep margin over the pulmonary artery was involved by tumor. The patient was given adjuvant radiation therapy to the mediastinum.

Discussion. Thymoma accompanies myasthenia gravis in approximately $12 \%$ of patients. The use of CPB for the resection of invasive thymomas ${ }^{1,2}$ and the performance of concomitant coronary artery bypass grafting and thymectomy $y^{3,4}$ have been described. Although invasion of the tumor into adjacent structures and cardiac entrapment of thymoma ${ }^{5}$ have been described, to the best of our knowledge there have been no reports of a thymoma entrapping a coronary vein graft.

In this case, the preoperative recognition of tumor entrapment of the only viable vessel to the heart tailored the work- 
up and surgical sequence. We chose a median sternotomy incision, believing it offered the best exposure for complete excision of the tumor, as well as redoing the bypass grafts. CPB was established via groin cannulas to support the heart during the redo sternotomy. Manipulation of the divided sternum was minimized, because thymomas can adhere to mediastinal structures, even without real invasion. Traction on the tumor or the vein graft might have led to an intraoperative myocardial infarction. Alternatively, a thoracotomy or thoracoscopy could have mobilized the mediastinum from the undersurface of the sternum before sternotomy, but we thought that this did not provide sufficient safety should the vein graft occlude.

A favorable outcome was achieved in this case by (1) preoperative coronary arteriography, (2) femoral CPB before the redo sternotomy, and (3) no manipulation of the tumor or graft before cardioplegia.

\section{REFERENCES}

1. Filippone G, Savona I, Tomasello V, Guzzetta P, Zarcone N, Agate V. Radical excision of invasive thymoma with intracaval and intracardial extension: a successful case report. J Cardiovasc Surg (Torino) 1997;38:547-9.

2. Fujino S, Tezuka N, Watarida S, Katsuyama K, Inove S, Mori A. Reconstruction of the aortic arch in invasive thymoma under retrograde cerebral perfusion. Ann Thorac Surg 1998;66:263-4.

3. Ohshima K, Ishikawa S, Yoshida I, Ohtaki A, Ohtani Y, Takahashi $\mathrm{T}$, et al. A concomitant operation of coronary artery bypass grafting and thymectomy: a case report [in Japanese]. Kyouba Geka 1994;47:1029-33.

4. Mendez-Fernandez MA, Kremem AF, Geis RC, Henly WS. Reconstruction of the left innominate vein in a patient with invasive thymoma undergoing coronary artery bypass surgery. J Cardiovasc Surg 1986;27:351-4.

5. Allums JA, Gordon FT, Moore CH. Cardiac entrapment by thymoma following coronary bypass surgery. Chest 1979;75:210-1.

\section{EXTERNALLY SUPPORTED RADIAL ARTERY GRAFT FOR MYOCARDIAL REVASCULARIZATION: A NEW TECHNIQUE TO AVOID VASOSPASM}

Luís A. O. Dallan, MD, Sérgio A. Oliveira, MD, Luiz F. Poli de Figueiredo, MD, Luiz A. Lisboa, MD, Fernando Platania, MD, and Adib D. Jatene, MD, São Paulo, Brazil

The radial artery was proposed as a conduit for coronary artery bypass many years ago, ${ }^{1}$ but its use was abandoned some years later because of a high incidence of arterial spasm, leading to narrowing or early graft occlusion. The development of new antispasmodic drugs led some surgeons, including us, to reevaluate the use of the radial artery for coronary artery bypass grafting, because arterial grafts are know to be more resistant to atherosclerosis than are autogenous vein grafts.,3 However, despite significant advances, such as improvements in radial artery removal technique and the use of calcium channel blockers, arterial spasm still may occur, causing concern for several surgeons. ${ }^{4}$ The aim of this report is to present a new technique that eliminates radial artery spasm when the artery is used as a coronary artery bypass graft.

From the Division of Cardiac Surgery, Heart Institute (InCor), Department of Cardiopneumology, University of São Paulo Medical School, São Paulo, Brazil.

Received for publication May 7, 1999; accepted for publication May 26, 1999.

Address for reprints: Luís A. O. Dallan, MD, Rua Inhambu, 917 Apt 191, São Paulo-SP-CEP 04520-013, Brazil (E-mail: expluiz@incor.usp.br).

J Thorac Cardiovasc Surg 1999;118:563-5

Copyright (C) 1999 by Mosby, Inc.

$0022-5223 / 99 \$ 8.00+0 \quad \mathbf{1 2 / 5 4} / \mathbf{1 0 0 2 8 1}$
Patients and methods. The Biocompound-graft (Alpha Research GmbH, Berlin, Germany) was developed as a new type of hybrid prosthesis, consisting of a highly flexible mesh tubing and the patient's own vein. Its primary indication is for coronary artery bypass, using venous bypass grafting, in patients with irregularly shaped veins. ${ }^{5}$ To our knowledge, this is the first report of this technique being used for an arterial graft. Detailed information and instructions for making and implanting the Biocompound-graft are available from the manufacturer.

The radial artery was harvested in a standard manner with topical application of warm saline solution and papaverine (1 $\mathrm{mL} / 100 \mathrm{~mL} 0.9 \% \mathrm{NaCl})$. The harvested artery was then prepared with the external support. In brief, the composite graft, consisting of a mesh tubing and the radial artery, is constructed with a fibrin adhesive. The Biocompound-graft is extremely pliable, made of individual filaments, $32 \mu \mathrm{m}$ thick, manufactured from a high-grade steel alloy (Phynox; Vena Tech, Evanston, Ill). After removal of the radial artery, a long, thin balloon catheter is carefully inserted through the distal end of the radial artery up to the proximal end. The applicator set with the Biocompound-graft mesh tubing is slipped over the radial artery, and the applicator is gently pushed off, leaving the mesh over the entire radial artery. The balloon is then gently inflated with isotonic solution, and the Biocompound-graft mesh is smoothed out starting at the middle of the balloon catheter and working toward both ends of 